the U.S. President, strongly urged the foundation of a depôt for the charts and instruments necessary for the navy; but it was not until 1830 that consent was given to this, when Lieut. Gouldsboro established one at Washington, the only astronomical equipment being a 30 -inch focus transit. Three years later the contents were removed to a room about $\mathrm{I} 4$ feet square on Capitol Hill. Here the equipment was increased by a $3 \frac{3}{4}$ in. transit, a Borda's circle, $3 \mathrm{ft}$. 6 in. focus achromatic, a portable transit, and sidereal clock. Up to this time the work of the institution entirely consisted of such astronomical observations as were necessary for the rating of chronometers. In 1838 a new epoch was entered upon by the instalment of Lieut. Gilliss, who at once improved the equipment and commenced systematic observations of the moon, eclipses and occultations, and also began the determination of right ascensions of standard stars. He soon reported to the Government that the housing of the instruments and charts was unsafe, and asked for better accommodation. It was not until I 842 , however, that this request was acceded to, but in that year a Bill was passed voting 25,000 dollars for a new observatory. To prepare for it, Gillis visited all the European observatories and gave orders for the best instruments then available. The site selected was close to the Potomac River, and about noo feet above the water.

In September 1844 , the new observatory was ready for use with a fine equipment of first-class instruments; but, strange enough, the man who had evolved the whole of the arrangements, Lieut. Gillis, was not selected as superintendent, this post being given to Lieut. Maury, who occupied the position until 186I. During his incumbency the chronograph was introduced into the observatory, and it is of interest to read that for the use of a magnetic clock, fillet chronograph and cylinder chronograph, Dr. Locke was in I849 paid the sum of 10,000 dollars. Maury's scheme of work was so wide that the reductions soon fell behind, and an enormous mass of work remained unpublished when he left in I86I. Gillis succeeded him, and again infused new life into the place. He resumed the meridian work, which had been almost neglected, and started to complete the reductions of previous observations. In June 1866, the observatory was relieved of a great part of its labour by the creation of the Hydrographic Office, which then took charge of all the charts, chronometers, sextants, \&c. Later on, however, in 1883 , most of this work came back to the institution. Daily time signals were originated in August 1865, by Prof. Harkness, and were transmitted by hand until 1879 , when an automatic tistributor was installed. The large 26 -inch object-glass was received in 1873 .

Magnetic observations had been started under Maury in I 845 , but no progress was made until $\mathrm{r} 887$, when a complete out fit was provided for obtaining continuous photographic records of all the magnetic elements.

In 1893 the observatory was again removed to its present site on Georgetown heights, 280 feet above the Potomac; it covers a circle having a radius of 1000 feet, and an area of about 70 acres. The principal work of the observatory is to carry forward a continuous series of meridian observations of the sun, moon, planets and ephemeris stars, which form the basis of the requisitions of the navy. Other work, however, has by no means been neglected, as is shown by the lengthy list of published observations and discoveries in the article. It is significant to notice that the magnetic observations have been entirely suspended at the new observatory since the summer of 1898 , the results being vitiated by the electric roads in the vicinity.

Use of Telephoto Lens in Astronomy,-Dr. Rudolf Steinheil, of the famous German firm of opticians, contributes to the British Fournal of Photography (vol. xlvi. p. 102) an article discussing, from experimental data, the extent to which the telephoto combination may be useful to astronomers. For stellar work he thinks it wili be little used, as for delineating fain objects it is unfitted on account of its relatively low speed, and for successfully defining double stars, \&c., it would necessarily have to be of large aperture. For the planets it is scarcely more fitted, the prolonged exposures necessary causing loss of definition owing to inaccuracies of following. The field of its use for astronomical purposes will probably thus only include the sun and moon. In the case of the moon the success wil depend on the degree of magnification required, as if this is pushed too far the image becomes feeble, and the difficulties due to the moon's motion in declination, which are not remediable by using a driving-clock, render the result uncertain. With the sun, however, all the difficulties encountered with other objects disappear, as the light available is sufficient to allow of instantaneous exposures with the largest amplifications. This Dr. Steinheil thinks will be the only permanent use of the telephoto lens for astronomical purposes, and he instances cases in which photographs of sun-spots, have been obtained measuring $7 \mathrm{~mm}$. without sacrificing detail.

Velocity of Mereors.-Prof. G. F. Fitzgerald writes in the Astrophysical Journal (vol. ix. p. 50, January 1899), suggesting the preparation for attempting to determine the velocity of the meteors during the next prominent showers. All that is required is an arrangement whereby a toothed wheel may be rotated in front of the camera lens during the exposure. The motion must be uniform, and we must know the rate of rotation and number of teeth on the wheel, and design these so that there may be two or more eclipses during the passage of the meteor across the field. Other methods of breaking up the image are given, such as an oscillatory motion of the lens or plate, or pointing the camera to a moving mirror; but in all these cases distortion of the star images would follow, and hence the advantage of the simple eclipsing arrangement.

It would probably be possible with some such arrangement as that suggested, to determine the meteor velocity with sufficient accuracy to show whether there is any sensible change due to the resistance of the atmosphere.

It is also evident that if two such cameras were employed at stations a considerable distance apart, and the same meteor caught by each, that the information given by the two would be extremely valuable.

\section{THE FISHES OF THE NILE.}

A MEMORANDUM regarding a proposed survey of the Nile, with the object of determining the species of fishes inhabiting its waters, has been drawn up by Dr. John Anderson, F.R.S., and is here printed in full, as it will interest all biologists. We are informed that the scheme, as detailed in the memorandum, has been sanctioned, and that Mr. W. Leonard S. Loat has been appointed superintendent. The only modification which has been made in the scheme, as detailed in the memorandum, affects the permanent use of a steam la,unch, as there was a practical difficulty in procuring one. The occasional use of a steam launch for trawling purposes will be available. This slight departure will in no way interfere with the efficiency of the survey.

Lord Cromer, whom Dr. Anderson approached on this subject in November last, has taken a most lively interest in the scheme throughout. The subjoined memorandum was drawn up at his request, and he has provided the funds necessary for the accomplishment of the Survey.

Our knowledge of the fishes of the Nile appears as yet to be very imperfect. It may be said to have taken its origin in $175^{\circ}$, when Hasselquist described thirteen species found in the deltaic area or in its immediate proximity. Since his time a number of distinguished men, e.g. Forskål, Geoffroy St.-Hilaire, Rüppell and others, have contributed by their observations personally carried out on the banks of the river to make its fishes more and more known.

By far the most important addition to our knowledge of the fishes of the Nile, after Hasselquist's day, was that made by Geoffroy St. -Hilaire in the "Description de l'Egypte," in which twenty-nine species were described and figured. Between 1829 and 1832, Rüppell published two valuable contributions to the subject. De Joannis, who accompanied an expedition to Luxor, somewhere about $1830-34$, seems to have undertaken a careful investigation of the fishes of that locality during his brief visit. The value attached to his work rested largely on the fact that his descriptions, which were published in 1835 , were illustrated by figures of each species drawn and coloured from life; more. over, he had not depended solely on the fishermen for his material, as not a few of the species were of no economic use and have not been rediscovered since. He described fourteen species in all, nine of which were new to science. His paper was supplemented by a list of all the known species of fishes inhabiting the Nile, including Rüppell's observations up to 1832 ; hence he enumerated fifty-three species.

In 1837 , the third contribution of Rüppell appeared; but he was seemingly unaware of Joannis's researches at Luxor, and consequently he mentioned only fifty-five in his summary of the species then known to inhabit the river. The fishes collected by Russegger in Egypt enabled Heckel, in 1847, to raise the NO. I 530, VOL. 59] 
number to sixty-seven species, excluding certain Barbels described by Riippell from Lake Tzana and some other species of doubtful origin. This number, however, was considerably in excess of the reality, as many of Heckel's species were afterwards found to be synonyms. Sixty probably represented the number of the known species at that time (1847). Petherick, while in Egypt in $186 \mathrm{I}-63$, made, at Dr. Günther's request, a collection of fishes for the British Museum. The specimens were obtained at Cairo, Khartum, and Gondokoro, and were described by Dr. Günther in an appendix to Petherick's "Travels," published in 1869. The collection contained eighteen new additions to the fauna, and raised the number of known species to eighty-two. It thus materially advanced our knowledge of the piscine fauna of the Nile ; and as Dr. Günther not only figured eight species, but at the same time added a description of every form, his contribution has proved most useful.

Since 1869 the fishes of the Nile have been almost completely neglected. Sauvage, however, in 1880 , added a new species from Lake Maryut; Pfeffer, in 1888, mentioned the species obtained by Stuhlmann in Egypt ; and Mitchell, in 1895 , brought to light and figured a new Chromis from Lake Menzaleh, and gave an account of the edible fishes of that lake. In 1896, Prof. Vaillant, in revising the Synodonts, pointed out the existence in the White Nile and at Khartum of two hitherto unrecognised forms.

At present, therefore, about ninety species of fishes are known to inhabit the river, but this number, considering the vast extent of its waterway and the very diverse physical conditions which characterise many parts of its course, cannot be considered as at all approaching finality.

The collections hitherto made from the Nile have principally been obtained from below the First Cataract ; indeed Rüppel and Petherick are the only two collectors who had opportunities to investigate the river above Assuan. The former distinguished traveller and naturalist largely collected in Lower Egypt, and not a few of Petherick's specimens were from the same region. In Dr. Günther's account of this collection only six species were distinctly recorded as coming from Gondokoro, Khartum, and the White Nile, while thirteen, besides the foregoing six, species were stated to belong properly to the reach of the Nile above the Sixth Cataract.

In dealing with the distribution of fishes in the Nile, the use of the phrase Upper Nile, unless what is meant by the term is clearly defined, leads to endless confusion. Dr. Guinther has made it quite evident in what sense he used the terms Lower and Upper Nile ; but it is to be feared that the latter term has generally been used in a wider sense, and has included the river from Philæ southwards to the Lakes. While we possess a fragmentary knowledge of the species from Khartum southwards, the immense tract of the Nile from the First to the Sixth Cataract remains practically untouched.

The great mass of the forms known from below the First Cataract is largely made up of edible species, and a careful consideration of the literature bearing on this part of the Nile favours the supposition that the collections of fishes which have been formed in the past have been chiefly obtained by the assistance of the fishermen along the banks of the river and from the fish-markets of the country. However, in a great river like the Nile, unique in its annual inundations and in other characters, a much more thorough course of procedure than the foregoing is absolutely necessary in order to obtain an accurate conception of the true nature of its fauna.

Apart from the mere knowledge of how many species of fishes exist in the river, great economic questions come to the front when their life-history is studied. These, however, can never be usefully worked out until there exists on record a basis on which to work, in the form of a detailed description of each species accompanied, as far as practicable, by a figure.

The inundations of the Nile exercise a powerful influence on the distribution of the fishes contained in its waters, while, on the other hand, the cataracts retard their range. A multitude of questions of great interest bearing on the life-history of the species thus at once suggest themselves in view of the physical features encountered in this marvellous river.

Moreover, as within the next few years a change will be effected in the distribution of the Nile waters by the construction of the controlling-powers now in course of erection at Philx and Assiut, and as other similar structures or dams are likely to follow toward the south, all of which are certain ultimately to limit more or less the range of certain species of fishes, it is much to be desired that, before any of these triumphs of the Department of Irrigation have been completed, we should be placed in possession of the main features and present condition of the piscine fauna of the great reaches of the river.

The present time seems also extremely opportune for the commencement of such an investigation, as the authorities of the Congo Free State have satisfactorily inaugurated a Survey of the Congo, and have already published some of the results. Were a corresponding Survey for the Nile entered upon by the Egyptian Government, and were the description of the species entrusted to Mr. G. A. Boulenger, F.R.S., who is describing the fishes of the Congo for the Congo Free State, and who is prepared to place his services at the disposal of the Egyptian Government free of all charge, the two surveys would mutually benefit each other, as the materials afforded by the one would throw light upon those of the other, many of the species of the two great rivers being closely allied. The results would doubtless be unique, and would form a lasting contribution to human knowledge, and, moreover, would be of great practical utility to both States.

The foregoing are a few of the grounds on which the proposed Survey is advocated.

\section{Scope of the Survey.}

It is recommended that some one who has had a zoological training should be appointed to superintend and carry out all the arrangements that it would be necessary to make for the formation of a representative collection of the fishes of the Nile, and who would be able likewise to discharge efficiently the other duties detailed in this memorandum. As it is very important that the form and life-colours of the different species should be accurately recorded by outline sketches, the Super. intendent should be qualified to carry out such a work, because the information which such drawings would afford, if made by one who had a correct eye for colour, would be of great use to Mr. Boulenger when he came to describe the individual species. The highly-finished drawings for the illustration of the volume of "The Fishes of the Nile" would be made in London under Mr. Boulenger's personal supervision. A colloquial kndwledge of Arabic would be of great advantage to the Superintendent, as it would enable him to obtain direct, from the fisher-folk on the banks of the river, much useful information on the subject of his investigations. Moreover, to properly discharge his various duties, the Superintendent should be a strong and healthy man.

An investigation of the entire river from the sea to Lado, and if possible through the sudd and rapids between Lado and Dufilé to its origin in the Albert Nyanza, should be kept in view as the ultimate aim of the Survey, which might be followed, later on, by similar researches into the fauna of the Nilotic lakes as a whole. Such a work is now proceeding on Lake Tanganyika, an intermittent effluent of the Congo, inaugurated by Mr. J. E. S. Moore, under the auspices of the Royal Society. Possibly when Mr. Moore has completed his work on that lake he may be able to direct his attention to Lake Kivu, and afterwards he might be in a position to cross the watershed to the Nile lakes and determine the character of their fauna as well, returning to civilisation by the Nile.

Although these are the lines on which a Survey of the Nile should be conducted to render it scientifically complete, it is suggested that the Survey should for the present be of a more limited character.

In the first instance, a series of stations should be selected along the river extending at intervals from the Delta, to Lado in the territory leased by the Egyptian Government to the Congo Free State, and as far to the south of this as possible. And it may be mentioned that were the Egyptian Government to inform the Secretary of State for the Congo Free State that an investigation into the fishes of the Nile was to be undertaken under its auspices, there is every reason to believe that the Secretary of State would issue orders for a collection of fishes to be formed by the Belgian officers at Lado and transmitted down the Nile to Cairo.

The following is a provisional list of the places recommended at which collections should be brought together, viz. Damietta, Lake Menzaleh, Rosetta, Lakes Burlus, Edku, and Maryut, Mahallet el Kebír, below the Barrage, above the Barrage, Cairo, Benisuef, Birket el Kurun (and two or three stations throughout the Fayum), Assiut, Luxor, Edfu, Assuan, Philæ, Korosko, Wádí Halfa, Akasheh, Dongola, Ambukol, Abu Hamed, 
Berber, Kassala, Khartum, Sennaar, Fashoda, Sobat and Lado, and possibly Dufilé and Wadelai.

It is suggested that all necessary instructions for collecting fishes should be issued in the form of a circular in English and Arabic, and should be sent to some responsible official in each of the foregoing localities accompanied by a collecting-box and alcohol, to be supplied by the Trustees of the British Museum, with the name of the locality burned into the wooden case containing the metal box holding the alcohol, on which the name of the station also should be indelibly scratched or engraved. The selection of the officials to whom the collecting should be entrusted would be a matter for the Government to decide; but it is suggested that Commandants of Stations, officers of the Royal Army Medical Corps, and officials connected with the Irrigation Department would be the most likely to take the greatest interest in the work. I speak from experience, because not a few of these officials gave me invaluable aid in the formation of the collections on which the first volume of the "Zoology of Egypt" is based. In nilitary stations, the black troops, when at leisure, are generally well pleased to assist in searching for living things, and were their successes rewarded by small pecuniary payments the results achieved by their agency might be considerable.

The services also of the fishermen along the river should be enlisted in the work, and were fair prices paid to them for the fishes they collected, and were they encouraged to procure as many kinds of fishes as possible, large and small, collections of considerable value would doubtless be forthcoming, and were they further instructed to net the very smallest fishes, in localities where there are backwaters, doubtless interesting and obscure species would be discovered.

The fishermen should also be utilised for obtaining the native names of the fishes throughout the different parts of the river, and it is suggested that each station should furnish a set of numbered specimens accompanied by a list giving the native name opposite to each number.

Should the Egyptian Government see its way to sanction this Survey, it is suggested that the officer in charge of the Museum of Natural History of the Medical School of Cairo should be entrusted with the reception of the collecting materials from the British Museum, with their distribution to the different collecting stations, with their reception when returned filled with fishes, and with the duty of forwarding them to London.

It is recommended that the distribution of the circulars and collecting-boxes should take place as soon as they are ready, and that they should be sent out to all the stations aforementioned, even to the most remote. In this way, many boxes would soon be returned filled, and, as they would at once be forwarded to London, the work of identifying the fishes might be proceeded with at once. By this plan, Mr. Boulenger would be placed in a position to offer valuable suggestions and to make known whenever the collections from a locality might require supplementing.

In not a few instances only the young of certain species might possibly be represented in a collection, or some of the specimens might be single examples of new or rare species which could only be satisfactorily made out by the aid of additional material. Mr. Boulenger having gone over the collection from one locality would thus be able, in returning the box for further material, to indicate clearly to the collector wherein his collection had been deficient. This could be done by the aid of an occasional figure of a fish when it was wanted, or even by the return of a specimen when more than one existed and more were required. It would also enable Mr. Boulenger to supply each station with a list of the species of fishes contained in each box, and by so doing contribute to stimulate the collectors to further exertions. Moreover, were preliminary lists of native and scientific names from a number of stations published at intervals and distributed among the stations, each collector would be in a position to judge of his relative success, especially in those cases in which the stations were situated on the same reach of the river. The native names of the fishes of the reach below the First Cataract are the same throughout the whole of its extent, whereas in many instances they differ materially from those in vogue between Berber and Lado. The reach from Philæ to Berber is so little known, in so far as its fishes are concerned, that preliminary lists from it would be invaluable, either in demonstrating uniformity or diversity of names in its own area, or as regards the reaches to the south and north of it.
Whilst the immediate distribution to the above-mentioned stations of instructions for collecting fishes, along with the necessary materials for so doing, is strongly advocated, it is equally desirable that in the beginning of the actual survey the attention of the officer in charge should be confined exclusively, in the first instance, to the river between Assuan and the sea. He should be constantly on the river at all seasons, and on his way down should visit the different stations, inspect the collections formed, satisfy himself that the specimens are properly preserved and that they are fairly representative. He should also particularly note the physical characters of the river at each station, find out as much as possible about the habits of the fishes, the depth at which they are found, the general character of the river-bed, the seasons in which the fishes breed, and the nature of their food. He should also satisfy himself that the native names have been correctly recorded in Arabic and rightly applied.

After the completion of the Survey from Assuan to the sea, the attention of the Superintendent should then be devoted to the reach of the river between Philæ and Berber, and after that has been attained he should proceed to investigate the interesting tract between the latter town and Lado.

To carry out his operations efficiently the Superintendent should be provided with a steam-launch, by means of which he would be placed in a position to use methods of fishing which it would be impossible to undertake by a sailing-boat. It would enable him to move freely up and down the reaches of the river which might require detailed investigation, and thus provide a means by which the Survey could be carried out in a thoroughly practical manner and with the least loss of time, as the nets at the disposal of the Superintendent might be constantly at work.

Other advantages of great importance would attend the use of a steam-launch in the way here advocated, as a cool airy room could be set apart for the storage of the specimens in alcohol, either in the course of preservation or finally preserved, and for the drying of the skins of fishes too large for conservation in alcohol. Moreover, the temperature of the contents of the boxes when the heat is great could, in such circumstances, be artificially reduced by simple means. The smooth joltless character of transit by water of boxes full of fishes recommends its adoption in preference to all other means; and, in connection with this, it may be mentioned that should it ever be necessary to send such boxes by railway train they should invariably be slung in complete shade. Transport by camels is out of the question.

The Superintendent should have the assistance of a native taxidermist to assist him in selecting the fishes as they are caught, in preparing and labelling them, and in changing the alcohol from time to time. His services would also be required in skinning the larger specimens.

On entering on the investigation of each new reach of the river from Assuan northwards, the Superintendent should secure the services, for a few days only, of three or four fishermen living on its banks and familiar with its fishing.grounds. Each party should be accompanicd by its own boat and nets, so that when their services were no longer wanted the fishermen could easily return to their villages.

The Superintendent should be furnished with appropriate nets, among which should be an eight-foot beam trawl; and it is recommended that his equipment in fishing-gear should be much the same as that supplied to the officer entrusted with the survey of the Congo River.

This memorandum is accompanied by some instructions, drawn up by Mr. Boulenger, for the preservation of fishes. ${ }^{1}$

$1 \mathrm{As}$ it is extremely desirable that any opportunity which may lend itself to the enlargement of our knowledge of the fauna of Egypt should be taken advantage of, it is therefore suggested that this Survey might, without much additional labour, do something towards making known the character of the Mammals found along the banks of the river, even as far as the margin the desert. This might be accomplished were the Superintendent to have various kinds and sizes of appropriately baited traps set every evening when the launch was moored for the night along the river's bank, but not the launch was moored for the night along the river's bank, but not
immediately in front of villages. They should be placed at wide intervals in zigzag lines reaching from the river to should be placed at wide intervals in zigzag lines reaching from the river to the desert; and likely situations for the presence of animal life, alternately on the two banks of the Nile, should be selected in determining where the launch is to remain for the night. Hares and animals of larger size should be prepared as skins, the skull and leg-bones of each specimen being left attached to the skin, the inside of which should be well smeared with arsenical soap. Specimens smaller than hares can be preserved in alcohol, but, as a rule, no mammal larger than an ordinary rat should be so treated, as the hair is apt to come expense. As many skins, therefore, as possible should be prepared, even of 


\section{Cost of the Survey.}

It is difficult to say what the annual cost of such a Survey as has been sketched would amount to. Were the Egyptian Government in a position to place a steam-launch at the disposal of the Survey, the cost of the working expenses, crew, and fuel, including the salary of the Superintendent and the pay of the taxidermist, should not exceed, under judicious management, more than $450 l$. to $500 l$. per annum for a period of three years.

The expenses would have been much greater had not the Director of the Natural History Departments of the British Museum undertaken to supply the necessary collecting-boxes, sixty in number, with alcohol to fill them. But apart from this there would be the initial cost of nets and other necessary apparatus, which may be put down at $20 l$.; but if the Superintendent were selected in England, his passage to and from Egypt would have to be met.

The cost of the transmission of the collecting-boxes from London to Cairo, as well as the cost of their return-carriage to London, would have to be borne by the Egyptian Government. The cost of publication would be about $1500 l$. This calculation is based on the probably correct supposition that one hundred plates would suffice for the illustration in a satisfactory manner of the fishes of the Nile. The cost of each plate would be $12 l$., so that $1200 l$. would be required for the illustration of the work, provided all the figures are uncoloured. The same number of plates in chromolithography would amount to nearly 2000 .

The printing of the text should not cost more than $300 l$., so that were $1500 l$. set apart for the bringing out of a volume uniform with the "Reptiles and Batrachians of Egypt," but with uncoloured plates, the total cost of the undertaking would be met by a grant of $3000 l$. spread over a period of three years. JOHN ANDERSON.

\section{I Harrington Gardens, London, January 12}

We, the undersigned, desire to express our general approval of the scheme detailed above for a Survey of the Nile, with the object of making known the species of fishes inhabiting its waters, and we beg to recommend it strongly to the favourable consideration of the Egyptian Government.

Lister, President of the Royal Society of London.

A. Günther, President of the Linnean Society of London.

E. Ray Lankester, Director of the Natural History Departments, British Museum.

P. L. SClater, Secretary of the Zoological Society of London.

HUNTER AND THE SCIENCE OF SURGERY.'

$\mathrm{N}$ accordance with the terms of a deed establishing the 1 Hunterian Oration, we celebrate to-day John Hunter's name and fame. Born on February 14 in the year 1728 at Long Calderwood, a small estate his father farmed, some eight miles from Glasgow, he died on October I6, I793, in his sixty-fifth year, celebrated alike as a great surgeon, a profound biologist, and a man of genius.

Here, in view of this noble presentment of Hunter by the foremost painter of his time, the orator is called upon to praise its foremost surgeon.

The picture was painted by Reynolds in 1785 , when Hunter was fifty-seven years old, and as we look at it we perceive him in deep reverie, in one of those waking dreams to which he refers in his lectures. He has paused from writing in order to think out some problem, and, as he often said, it was a delight to him to think. As we dwell upon the features we cannot doubt that a sudden inspiration has flashed upon and gradually pervaded his mind, some great scientific truth or generalisation which he has grasped, and is pondering with intense satisfaction.

Buckle, in his "History of Civilisation," writes : "It sometimes seems as if Hunter's understanding were troubled by the grandeur of its own conceptions, and doubted the path it ought to take. Still, his powers were so extraordinary, that among

the smaller mammals. Before specimens are placed in alcohol they should have the abdomen slit open to admit of the spirit having free access to the visce the viscera. The date of capture, the character of the ground on which the should be entered in the day-book opposite to a number corresponding to should be entered in the day-book opp

1 Abstract of the Hunterian Oration delivered by Sir William MacCormac, Bart,, K.C.V.O., President of the Royal College of Surgeons of England, at the College, on February I $_{4}$.

$$
\text { NO. I 530, VOL. 59] }
$$

the great masters of Organic Science he belongs to the same rank as Aristotle, Harvey, and Bichat, and is somewhat superior to Haller and Cuvier."

To appreciate, or even fully to comprehend, the labours of Hunter, one must strive to judge them from the standpoint of his time, for in this way only can we form a just conception of their splendid superiority.

On Hunter's early life and the many moot points it involves -his preliminary education, whether he was for a time a carpenter by trade, why he was not sent to Glasgow College like his brothers, or why in later life he spent some time at Oxford University without being in the least appreciative of the training he might there take advantage of-I do not purpose to dwell. William Hunter desired his brother John should be trained as a physician, and sent him to Oxford to obtain the necessary classical education, but during the short period he spent there he found himself quite unable to study Latin and Greek, and spoke afterwards rather contemptuously of the ancient learning.

Hunter's scientific career dates from his arrival in London in I748, where, when twenty years of age, he joined his brother William's school as an ill-educated youth, new to all the amenities of life, brusque in manner and negligent in appearance, yet with a keen sense of physical enjoyment. As a pupil he showed a marvellous aptitude for anatomy, and soon became a successful teacher of it, but he always remained a learner in that book of nature which was ever open before him, and whose pages, until he died forty-five years later, he never ceased to turn, interpreting aright many of its obscurest passages.

In 1759 , undermined in health by ten years of incessant toil, he obtained an appointment in the army and sailed with Keppel for Belleisle, and afterwards accompanied the expedition into Portugal. It was there that he studied the phases of inflammation and the treatment of gunshot wounds.

When he returned to London, with nothing but his half-pay to provide the wherewithal to live upon, and nothing but his genius to trust to for advancement, Hunter's life became one of untiring labour. He was elected a Fellow of the Royal Society when thirty-nine, a year later became surgeon to St. George's Hospital, and in 1776 was appointed Surgeon Extraordinary to the King.

In 1786 he was appointed Deputy Surgeon-General in the army, and three years later became Surgeon-General. He also published his work on Venereal Diseases in I 786, and the following year received the Copley Medal from the Royal Society on account of many valuable papers. His great work on the "Blood and Inflammation," however, still remained unfinished after thirty years of labour bestowed upon it, and was only published after his death.

At fifty years of age he had reached the zenith of his surgical career, having done more to improve the science of surgery than all the other surgeons of Europe had done before him.

On the death of Pott, Hunter became the chief surgical authority in London; his opinion was highly valued in difficult cases, and he acquired a lucrative practice. There is no doubt he was an admirable clinical teacher and a courageous operator, and although his systematic lectures on surgery were marred by a faulty delivery and occasional obscurity of style, they attracted all those who afterwards attained distinction anongst their contemporaries.

The evidence of Cline, Abernethy, Astley Cooper, Royer Collard, Billroth-surgeons indeed of every school-emphasise the excellence of these lectures on the Principles of Surgery, and it is still evident to the reader of to-day in the somewhat fragmentary record which has been preserved by Hunter's pupils.

Hunter was deficient in what we are pleased to call general culture, and doubtless he suffered in consequence. He read but little, and many of his discoveries had been anticipated by others, but when this was brought to his knowledge he abandoned any claim he might have advanced. It appeared to him of small consequence by whom a discovery was made if it only proved the stepping-stone to a higher and more complete knowledge. He was no mere collector of facts in order simply to augment their number. He thought too much attention could not be paid to facts so long as they helped to establish principles, and in the capacity for generalisation Hunter was pre-eminent. He had a great power of estimating what was worth doing, and how best to do it, his descriptions are graphic, and as an expositor of what he had to tell he is often unsurpassed. 